\title{
Low-Temperature Metal Induced Crystallization of Amorphous Silicon Using Nano-Nickel Particles*
}

\author{
Chuen-Shii CHOU**, Der-Ho WU**, Ru-Yuan YANG*** and Feng-Cheng CHOU** \\ ** Department of Mechanical Engineering, National Pingtung University of Science and Technology, \\ Pingtung 912, Taiwan \\ E-mail:cschou@mail.npust.edu.tw \\ *** Department of Material Engineering, National Pingtung University of Science and Technology, \\ Pingtung 912, Taiwan
}

\begin{abstract}
A simple method was presented to conduct the low-temperature metal induced crystallization of an amorphous silicon (a-Si) film using nano-sized nickel particles. The effects of the annealing temperature and the duration on the morphology and the crystallized size of the induced polycrystalline silicon (poly-Si) film were investigated using a field emission scanning electron microscope (FE-SEM), a twin thin-film X-ray diffractometer (XRD), a Raman spectrometer, and an energy dispersive spectrum (EDS). In addition, the residual nickel and the I-V characteristics of the poly-Si film were measured using a secondary ion mass spectrometer and a semiconductor parameter analyzer, respectively. The crystalline peak of $\mathrm{Si}$ (311) was obviously detected even at an annealing temperature of $400^{\circ} \mathrm{C}$ and the duration of $1 \mathrm{~h}$. The crystallization temperature was lowered due to the high activity of the nano-nickel particles. Therefore, this study supports the feasibility of applying nano-nickel particles to crystallize the a-Si film.
\end{abstract}

Key words: Metal Induced Crystallization, Nano-Nickel, Polycrystalline Silicon

\section{Introduction}

In recent years, polycrystalline silicon (poly-Si) has attracted substantial interest because of its effective use in electronic components, such as the thin film transistor (TFT), the solid-sate junction solar cell, and so on. Solid phase crystallization (SPC) is a conventional and common method employed to crystallize amorphous silicon (a-Si), whose crystallization temperature is about $600{ }^{\circ} \mathrm{C}$. However, this temperature is so high that SPC cannot be applied to crystallize the a-Si film on a glass substrate with a large area ${ }^{(1)}$.

Metal induced crystallization (MIC) is an alternate technique to fabricate the poly-Si. For instance, the aluminum $(\mathrm{Al})^{(2)}$, the copper $(\mathrm{Cu})^{(3)}$, the aurum $(\mathrm{Au})^{(4)}$, the silver $(\mathrm{Ag})^{(5)}$, and the nickel $(\mathrm{Ni})^{(1,6-11)}$ were used to crystallize the a-Si film, respectively. Most importantly, the crystallization temperature needed in MIC is lower than that required in SPC. Most of the aforementioned references on nickel metal induced crystallization (Ni-MIC) concerned depositing a Ni film on the top of an a-Si film using an electron beam evaporator $^{(4,6,8)}$, or a sputter ${ }^{(9)}$, which is a more expensive facility. Although Yoon et al. ${ }^{(1)}$ used a spin coater to deposit a $\mathrm{Ni}$ film on the top of an a-Si film, the crystallization temperature and the duration were up to $500^{\circ} \mathrm{C}$ and $10 \mathrm{~h}$, respectively. So far, the feasibility of applying nano-sized nickel particles to crystallize the a-Si film on the silicon substrate at an annealing temperature $\left(<500^{\circ} \mathrm{C}\right)$ and a duration $(<2 \mathrm{~h})$ has seldom been studied.

Therefore, this study presented a simple metal induced method of crystallizing the a-Si

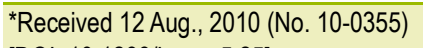
[DOI: 10.1299/jmmp.5.25]

Copyright $\odot 2011$ by JSME 
film using nano-sized nickel particles to reduce the crystallization temperature and the duration, and it also examined the crystallization mechanism. In addition, the effects of the annealing temperature and the duration on the surface morphology, the grain size, the residual nano-sized nickel, and the I-V characteristics of the induced poly-Si film induced by nano-sized nickel particles were investigated.

\section{Experimental Apparatus and Procedures}

\subsection{The procedure of MIC using nano-sized nickel}

The selected substrate herein was a 6-inch wafer of monocrystalline silicon, which was cleaned first and dried using a nitrogen gun. A silicon dioxide $\left(\mathrm{SiO}_{2}\right)$ film with a thickness of $200 \mathrm{~nm}$ was deposited on the top of wafer using the atmospheric pressure chemical vapor deposition (APCVD). An a-Si film with a thickness of $200 \mathrm{~nm}$ was deposited on the top of $\mathrm{SiO}_{2}$ film using the plasma enhanced chemical vapor deposition (PECVD) with a temperature of $300{ }^{\circ} \mathrm{C}$, a deposition rate of $77 \mathrm{~nm} / \mathrm{min}$, and at a pressure of $10^{-3}$ torr. Then this substrate, with a $\mathrm{SiO}_{2}$ film and an a-Si film, was cut into several square pieces $(1 \mathrm{~cm} \times$ $1 \mathrm{~cm})$ using a diamond cutter blade.

The solution, which was prepared by mixing $0.01 \mathrm{~g}$ nano-sized nickel particles with a mean diameter of $20 \mathrm{~nm}$ in the $200 \mathrm{ml}$ alcohol, was homogenized for $1 \mathrm{~h}$ in an ultrasonic cleaner (Delta $\mathrm{DC} 150 \mathrm{H}$ ), and then it was dripped on the top of a-Si film of each square piece using a burette. These square test pieces were dried at room temperature for 10 min. The test piece was annealed in a high-temperature furnace (Thermolyne 46100) filled with argon gas. The annealing temperature that ranges from 400 to $600{ }^{\circ} \mathrm{C}$ was used to crystallize the a-Si film with the help of the nano-sized Ni particles. Table 1 presents the test conditions under which the test pieces were annealed herein. As the temperature lowered to room temperature, the test piece was dipped in the solution of etching for $1 \mathrm{~min}$ to remove the residual nano-sized Ni particles. The rate of etching residual nano-sized $\mathrm{Ni}$ particles was $29 \mathrm{~nm} / \mathrm{min}$. The solution of etching used herein was prepared by mixing $80 \% \mathrm{H}_{3} \mathrm{PO}_{4}, 5 \%$ $\mathrm{HNO}_{3}, 5 \% \mathrm{HAC}$, and $10 \% \mathrm{H}_{2} \mathrm{O}$, and then homogenizing in an ultrasonic cleaner for $1 \mathrm{~h}$ at a temperature of $50{ }^{\circ} \mathrm{C}$.

Table 1 Test conditions and grain size.

\begin{tabular}{ccccc}
\hline & $\begin{array}{c}\text { Mass of Ni } \\
(\mathrm{g})\end{array}$ & $\begin{array}{c}\text { Anneal Temperature } \\
\left({ }^{\circ} \mathrm{C}\right)\end{array}$ & $\begin{array}{c}\text { Anneal Time } \\
(\mathrm{hr})\end{array}$ & $\begin{array}{c}\text { Grain Size } \\
(\mathrm{nm})\end{array}$ \\
\hline Test 1 & & \multirow{2}{*}{400} & 1 & 1.29 \\
Test 2 & & & 3 & 2.21 \\
Test 3 & \multirow{2}{*}{0.01} & 500 & 1 & 7.39 \\
Test 4 & & & 3 & 11.09 \\
Test 5 & & \multirow{2}{*}{600} & 1 & 19.41 \\
Test 6 & & & 3 & 51.77 \\
\hline
\end{tabular}

\subsection{Measurements of the characteristics of the induced poly-Si film}

The micrographs of the induced poly-Si film on the substrate were obtained using a field emission scanning electron microscope (FE-SEM) (Hitachi S-4800) with a magnification of $100 \sim 500,000 \times$. A twin thin-film X-ray diffractometer (XRD) (Bede D1 HR-XRD) was used to obtain the XRD patterns of the induced poly-Si film. An energy dispersive spectrum (Horiba EX-200) was used to analyze the weight ratios of the element in the induced poly -Si film and to detect the residual Ni particles on the substrate.

A Raman spectrometer (Jobin-Yvon T64000) was used to confirm the formation of the poly-Si on the substrate. A secondary ion mass spectrometer (Cameca IMS-6f) was used to 
show the variation of the residual nano-sized Ni particles with the depth. In addition, a semiconductor parameter analyzer (Agilent HP4145B) was used to measure the I-V characteristics of the induced poly -Si film.

\section{Results and Discussion}

\subsection{The microstructure of the induced poly-Si film}

Figure 1 presents the FE-SEM micrographs $(100 \mathrm{k} \times)$ and the EDS analyses of the induced poly-Si film, which has already been etched. Fig. 1 has six panels. (a) In the left-top panel, the image of the induced poly-Si film in Test $2\left(400{ }^{\circ} \mathrm{C}, 3 \mathrm{~h}\right)$ is presented; (b) in the right-top panel, the image and the EDS analysis of the induced poly-Si film in Test 1 $\left(400{ }^{\circ} \mathrm{C}, 1 \mathrm{~h}\right)$ are presented; (c) in the left-central panel, the image of the induced poly-Si film in Test $4\left(500{ }^{\circ} \mathrm{C}, 3 \mathrm{~h}\right)$ is presented; (d) in the right-central panel, the image and the EDS analysis of the induced poly-Si film in Test $3\left(500{ }^{\circ} \mathrm{C}, 1 \mathrm{~h}\right)$ are presented; (e) in the left-bottom panel, the image of the induced poly-Si film in Test $6\left(600{ }^{\circ} \mathrm{C}, 3 \mathrm{~h}\right)$ is presented; and (f) in the right-bottom panel, the image and the EDS analysis of the induced poly-Si film in Test $5\left(600{ }^{\circ} \mathrm{C}, 1 \mathrm{~h}\right)$ are presented. The average area occupied by nano-sized nickel particles on the a-Si film $\left(1 \mu \mathrm{m}^{2}\right)$ is about $30.3 \mathrm{~nm}^{2}$

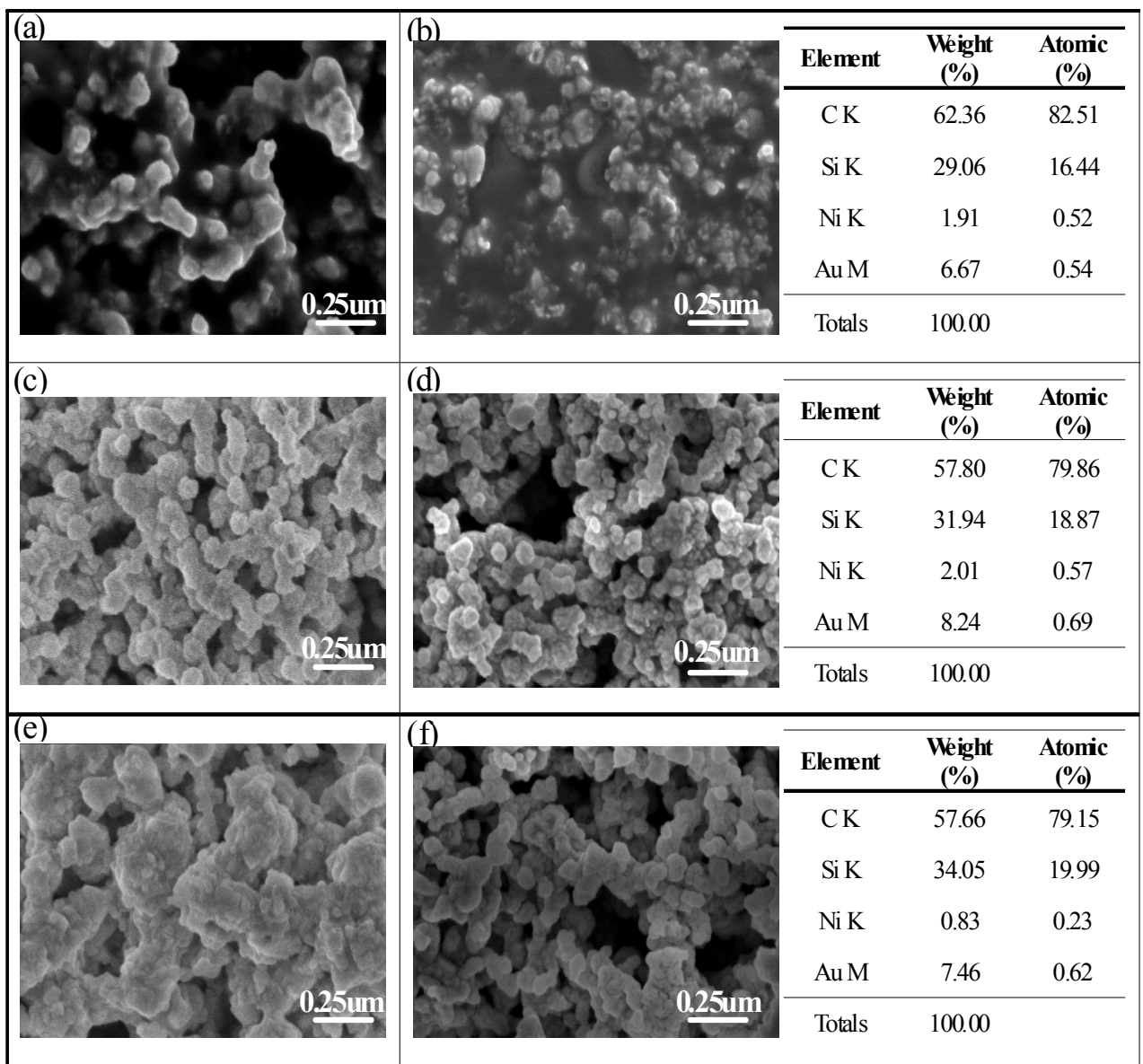

Fig. 1 FE-SEM micrographs and the EDS analyses of the induced and etched poly-Si film.(a) Test $2\left(400^{\circ} \mathrm{C}, 3 \mathrm{~h}\right)$, (b) Test $1\left(400^{\circ} \mathrm{C}, 1 \mathrm{~h}\right)$, (c) Test $4\left(500^{\circ} \mathrm{C}, 3 \mathrm{~h}\right)$, (d) Test 3 $\left(500^{\circ} \mathrm{C}, 1 \mathrm{~h}\right),(\mathrm{e})$ Test $6\left(600^{\circ} \mathrm{C}, 3 \mathrm{~h}\right)$, and (f) Test $5\left(600^{\circ} \mathrm{C}, 1 \mathrm{~h}\right)$.

As the annealing temperature increases, the weight ratio of the element of silicon in the poly-Si film increases and the weight ratio of the residual $\mathrm{Ni}$ particles in the poly-Si film decreases. At a fixed annealing duration of $1 \mathrm{~h}$, the weight ratio of the element of silicon 
increases from 29.06 to $34.05 \%$, and the weight ratio of the residual $\mathrm{Ni}$ particles decreases from 1.91 to $0.83 \%$, as the annealing temperature increases from 400 to $600{ }^{\circ} \mathrm{C}$ (Fig. 1). The grain size obtained by Debye-Scherrer equation ${ }^{(12)}$ also increases with increase in annealing temperature or duration. For instance, at a fixed annealing duration of $1 \mathrm{~h}$, as the annealing temperature increases from 400 to $600^{\circ} \mathrm{C}$, the grain size of silicon increases from 1.29 to $19.41 \mathrm{~nm}$ (Table 1). Moreover, at a fixed temperature of $500{ }^{\circ} \mathrm{C}$, the grain size of silicon increases from 7.39 to $11.09 \mathrm{~nm}$ as the duration increases from 1 to $3 \mathrm{~h}$. These results are probably attributed to the fact that a larger input energy corresponds to a higher moving rate of molecules, which induces a higher rate of grain growth. Aside from this, the poly-Si films shown in Fig. 1 are porous because the solution of nano-sized nickel particles with a mean diameter of $20 \mathrm{~nm}$ was only dripped on the top of a-Si film without using any sophisticated coating technique (Fig. 2). Further, the thickness of $\mathrm{SiO}_{2}$ film (or poly-Si film) may not be substantially decreased during the process of etching residual nano-sized Ni particles because the solution used herein is for removing the residual Ni particles. Aside from this, the solution usually used to etch $\mathrm{SiO}_{2}$ is the hydrofluoric acid (HF).
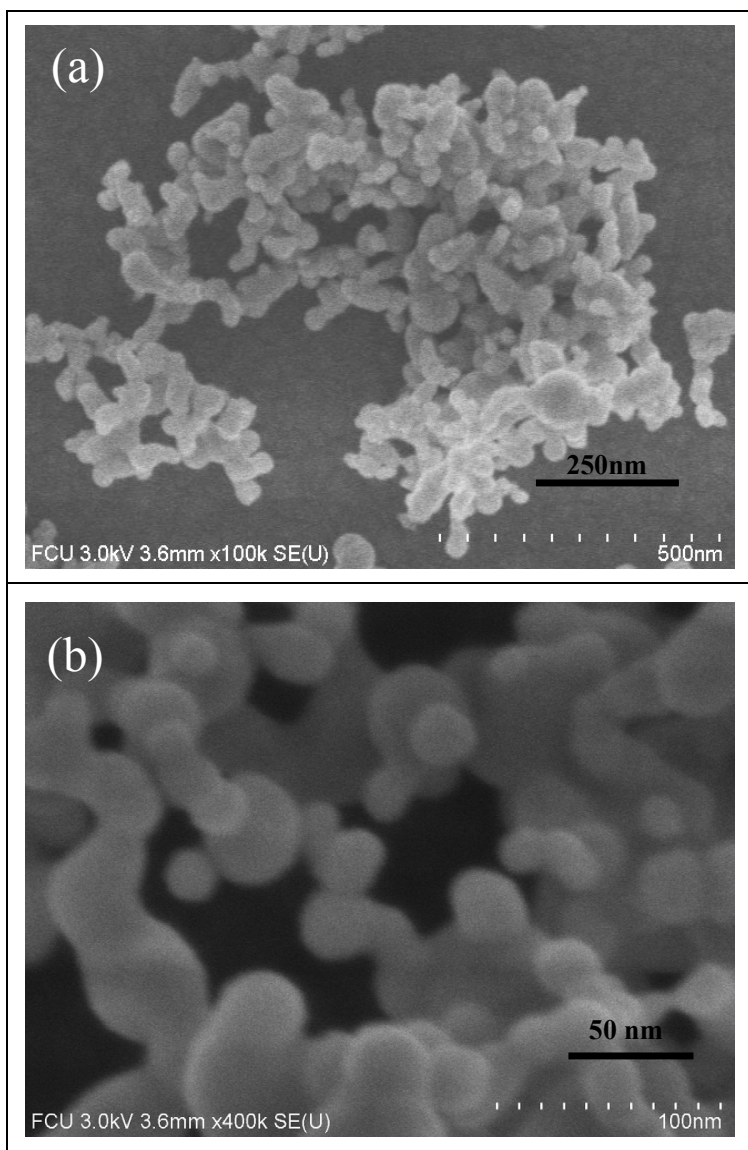

Fig. 2 FE-SEM micrographs of nano-sized nickel particles on the top of a-Si film. (a) $100 \mathrm{k}^{\times}$, (b) $400 \mathrm{k}^{\times}$.

Figure 3 shows XRD patterns of the induced poly-Si film. Fig. 3 has two panels: (1) the left panel refers to the duration of $1 \mathrm{~h}$; and (2) the right panel refers to the duration of $3 \mathrm{~h}$. The crystalline peak of silicon (311) is obviously detected even at an annealing temperature of $400{ }^{\circ} \mathrm{C}$ and the duration of $1 \mathrm{~h}$. These results are probably attributed to the fact that the nano-sized nickel particles inherit the high activity. Moreover, the peak intensity increases with increase in the annealing temperature, so increasing the annealing temperature facilitates the crystallinity of the silicon. 


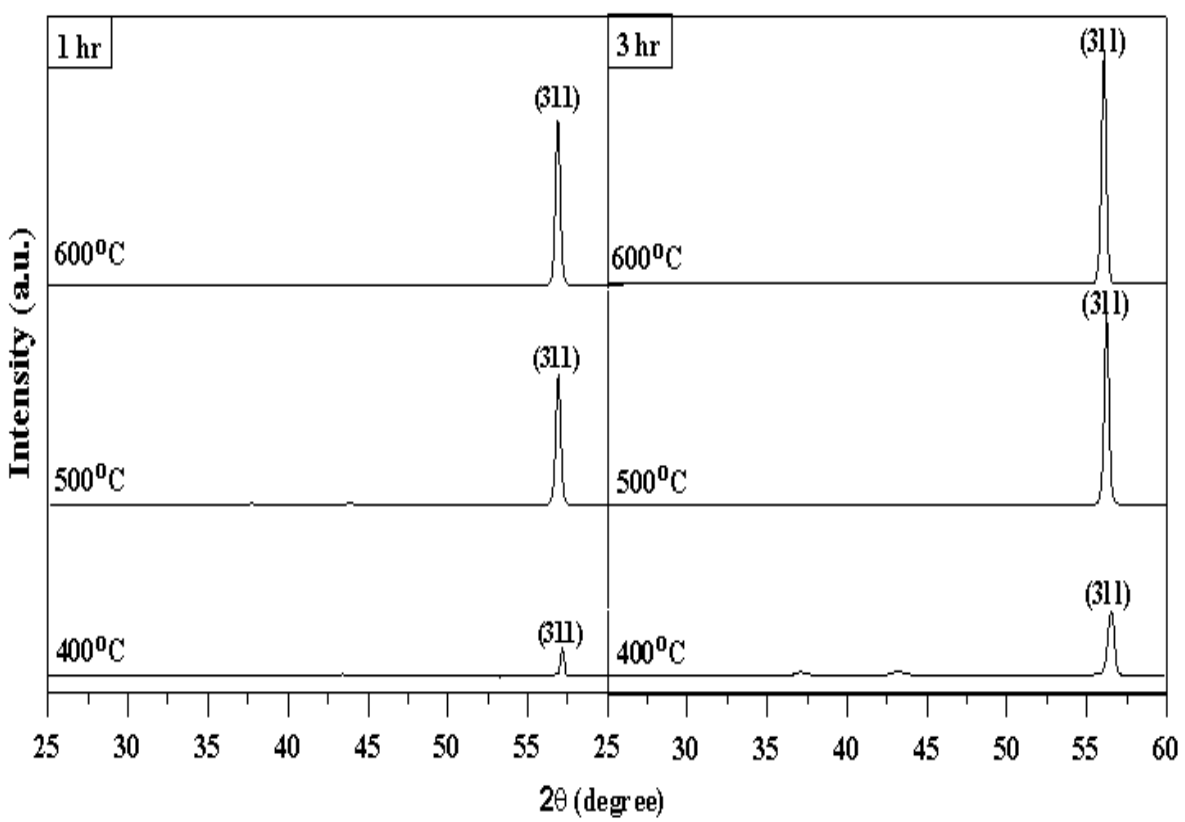

Fig. 3 XRD patterns of the induced and etched poly-Si film.

Figure 4 shows the Raman spectra of the induced poly-Si films in Tests 1-6. Fig. 4 has two panels: (1) the left panel refers to the duration of $1 \mathrm{~h}$; and (2) the right panel refers to the duration of $3 \mathrm{~h}$. The spectra have an Si-Si TO-like band at about $510-520 \mathrm{~cm}^{-1}$, due to the polycrystalline Si phase. This result supports the applicability of the nano-sized nickel particles for the Ni-MIC. In addition, the intensity of the peak increases with increase in the annealing temperature.

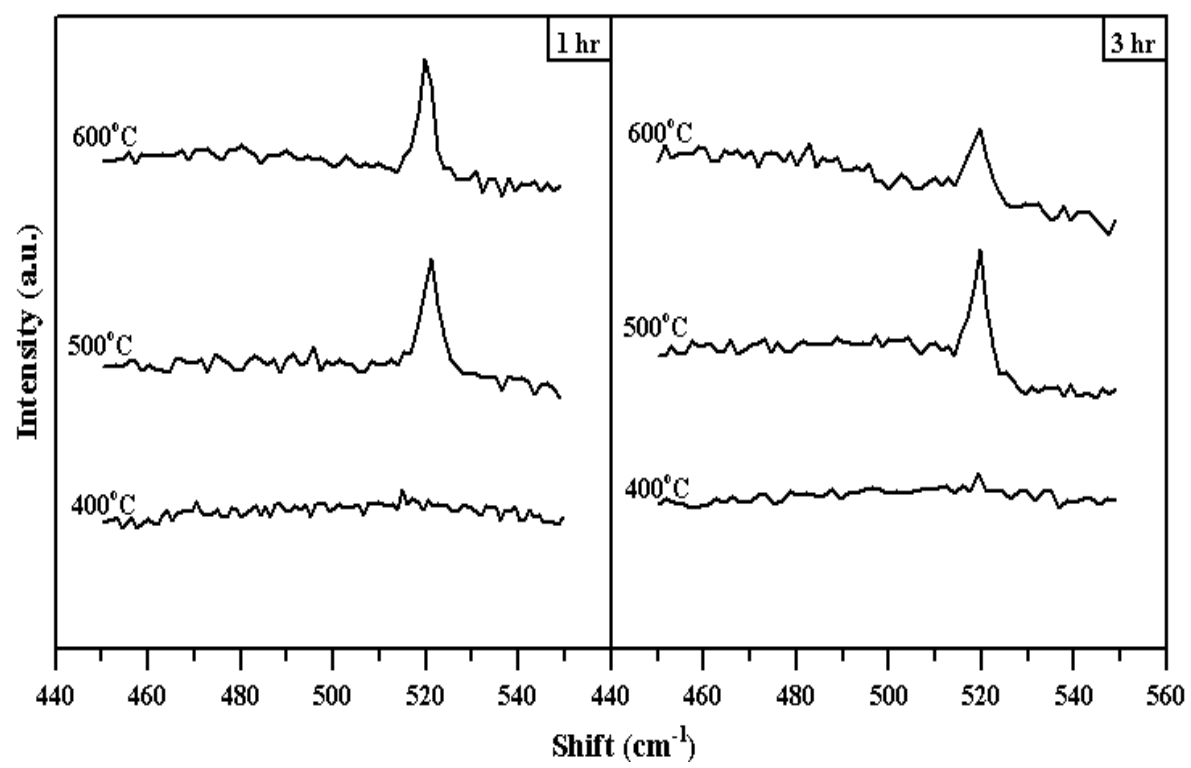

Fig. 4 Raman spectra of the induced and etched poly-Si film.

Figure 5 depicts the mechanism of Ni-MIC obtained using the nano-sized nickel particles. (1) Nano-sized nickel particles on the top of a-Si film occupies the space between $\mathrm{Si}$ atoms, and then the Guun effect is induced during annealing; (2) the free electrons from the $\mathrm{Ni}$ particles interact with the covalent $\mathrm{Si}$ bonds, and the nickel silicide ( $\mathrm{NiSi}_{\mathrm{x}}$ ) is produced; (3) the re-crystallization of the $\mathrm{Si}$ atoms occurs at the interface because of the latent heat released from $\mathrm{NiSi}_{\mathrm{x}}$, and the poly-Si is formed. Therefore, this reaction improves the crystallization of a-Si, and declines the crystallization temperature. 

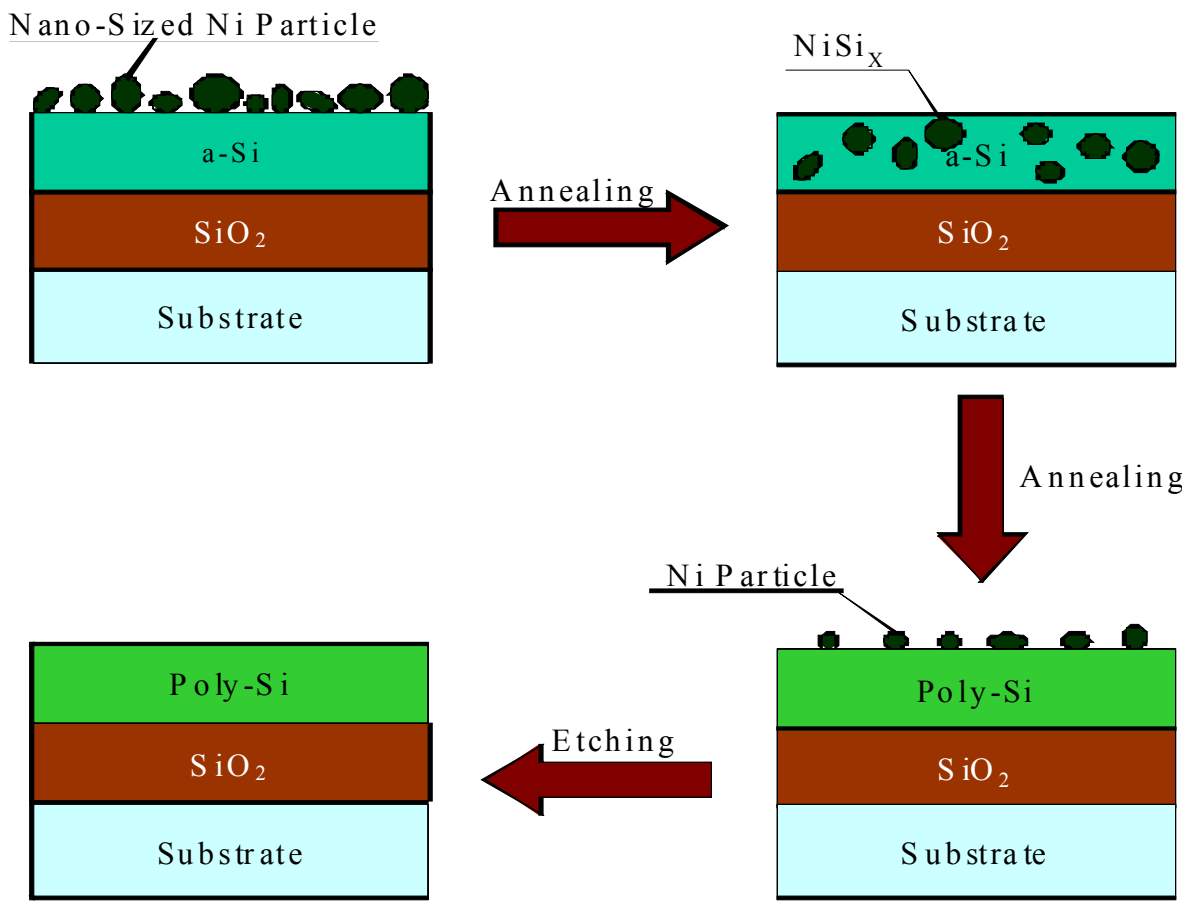

Fig. 5 Schematic of the mechanism of Ni-MIC obtained using nano-sized nikel particles.

\subsection{The residual Ni and I-V characteristics of the induced poly-Si film}

Figure 6 shows the variations of the residual nickel with the depth of the test piece in Test $3\left(500^{\circ} \mathrm{C}, 1 \mathrm{~h}\right)$. As the depth of the test piece changes from $0 \mathrm{~nm}$ (i.e. the top of poly-Si film) into $300 \mathrm{~nm}$ (i.e. the bottom of the poly-Si film), the residual nickel decreases from $3 \times 10^{20}$ to $5 \times 10^{18} \mathrm{c} / \mathrm{s}$, approximately. Gall et al. suggested that the poly-Si film with a higher residual metal used for inducing the crystallization of a-Si film can be used as the back surface field (BSF) of the n-p junction solar cell ${ }^{(13)}$. In addition, the residual nano-sized particles (such as nickel particles used herein) in the poly-Si film can be reduced by increasing the duration of etching to meet the requirement of the active layer of the solar cell with a thin-film of silicon ${ }^{(13)}$.

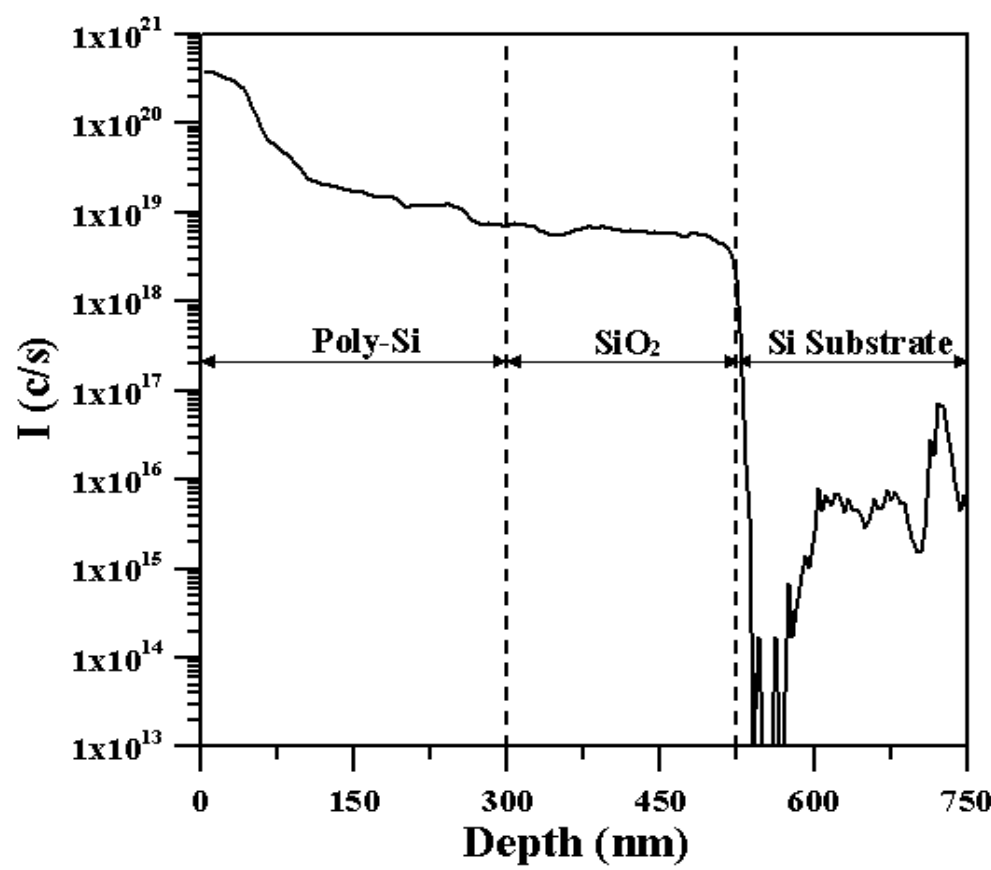

Fig. 6 The variation of the residual nickel with the depth of the test piece in Test 3. 
Figure 7 shows the I-V characteristics of the poly-Si film in Test $3\left(500{ }^{\circ} \mathrm{C}, 1 \mathrm{~h}\right)$, Test 4 $\left(500{ }^{\circ} \mathrm{C}, 3 \mathrm{~h}\right)$ and Test $5\left(600^{\circ} \mathrm{C}, 1 \mathrm{~h}\right)$. In general, the dark current density increases with increase in the biased voltage, but its value is quite small. Therefore, the corresponding resistance is pretty large, and the averaged values of the resistance in Tests 3,4 and 5 are $5.76 \times 10^{12}, 5.76 \times 10^{12}$, and $5.76 \times 10^{12}$, respectively. As the voltage exceeds $0.5 \mathrm{~V}$, at a fixed duration of $1 \mathrm{~h}$, the dark current in Test $5\left(600^{\circ} \mathrm{C}\right)$ always exceeds that in Test $3\left(500{ }^{\circ} \mathrm{C}\right)$. In addition, at a fixed annealing temperature of $500{ }^{\circ} \mathrm{C}$, the dark current in Test $4(3 \mathrm{~h})$ substantially exceeds that in Test $3(1 \mathrm{~h})$. These results are probably attributed to the fact that increasing the annealing temperature (or extending the annealing duration) facilitates the grain size of the silicon, which may affect the dark current density of the poly-Si film. Furthermore, as the dark current density is less than $10^{-7} \mathrm{~A} / \mathrm{cm}^{2}$ in all tests, the induced poly-si thin films have a potential for being used as the thin film materials of the optic-electrical devices.

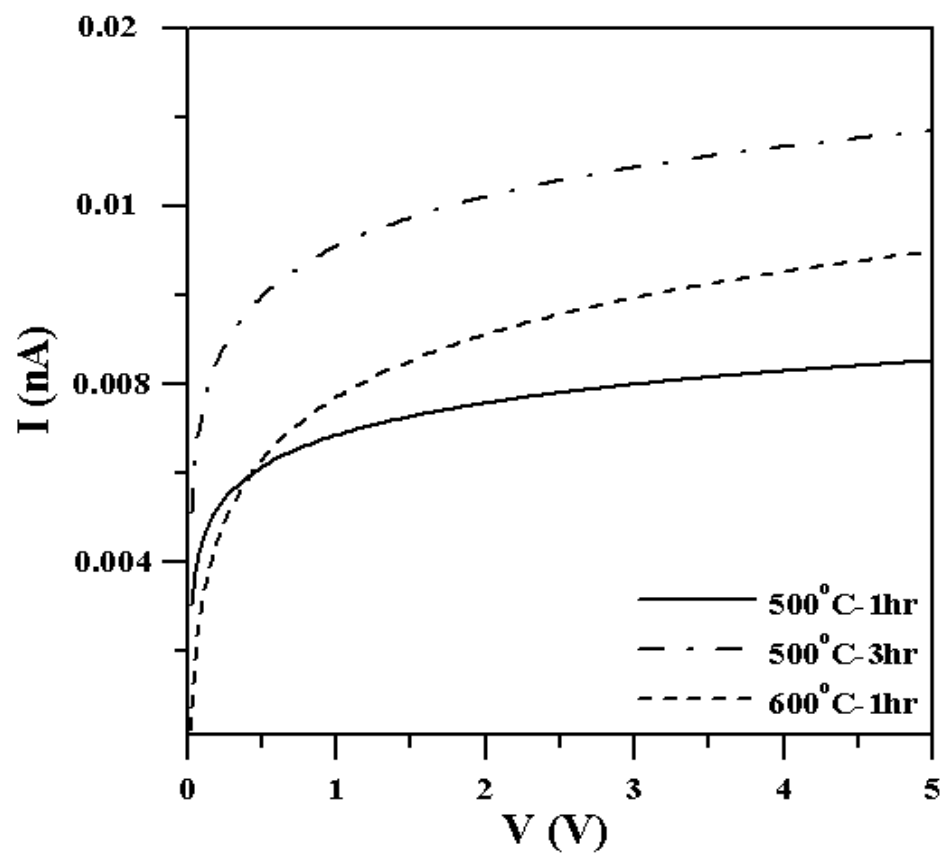

Fig. 7 The I-V characteristics of the poly-Si film in Test $3\left(500^{\circ} \mathrm{C}, 1 \mathrm{~h}\right)$, Test $4\left(500^{\circ} \mathrm{C}\right.$, $3 \mathrm{~h})$ and Test $5\left(600^{\circ} \mathrm{C}, 1 \mathrm{~h}\right)$.

\subsection{Conclusion}

A poly-Si film induced by nano-nickel particles was fabricated and investigated. The crystalline peak of $\mathrm{Si}$ (311) is obviously detected even at an annealing temperature of $400{ }^{\circ} \mathrm{C}$ and duration of $1 \mathrm{~h}$. The grain size of silicon in the poly-Si film also increases with increase in annealing temperature. Although the crystallization temperature of the a-Si could be lowered to $400{ }^{\circ} \mathrm{C}$, the grain size of silicon should be improved. Most interesting, this study supports the feasibility of applying nano-nickel particles to crystallize the a-Si film.

\section{Acknowledgment}

The authors would like to thank the National Science Council, R.O.C., Taiwan for financially supporting this research under contract NSC 98-2221-E-020-034. This work is the revision and extension of the paper in RE2010 International Conference in Yokohama with the paper number 00536 . The opportunity is gratefully acknowledged. 


\section{References}

(1) Yoon, S. Y., Kim, K. H., Kim, C. O., "Low temperature metal induced crystallization of amorphous silicon using a Ni solution,"J. Appl. Phys, Vol.82 (1997), pp. 5865.

(2) Zou, M., Cai, L., Wang, H., Brown, W., "Nano-aluminum-induced crystallization of amorphous silicon,"Mater. Lett, Vol.60 (2006), pp. 1379-1382.

(3) Russel, S. W., Li, J., Mayer, J. W., "In situ observation of fractal growth during a-Si crystallization in a Cu$u_{3}$ Si matrix,"J. Appl. Phys, Vol.70 (1991), pp. 5153.

(4) Yang, R. Y., Weng, M. H., Liang, C. T., Su, Y. K., Shy, S. L., "Low Temperature Metal Induced Crystallization of Amorphous Silicon by Nano-Gold-Particles," Jpn. J. Appl. Phys, Vol.45 (2006), pp. 1146-1148.

(5) Bian, B., Yie, J., Li, B., Wu, Z., "Fractal formation in a-Si:H/Ag/a-Si:H films after annealing,"J. Appl. Phys, Vol.73 (1993), pp. 7402.

(6) Li, J. F., Sun, X. W., Yu, M. B., Qi, G. J., Zeng, X. T., "Nickel induced lateral crystallization behavior of amorphous silicon films,"Applied Surface Science, Vol.240 (2005), pp. 155.

(7) Behnam, A., Karbassian, F., Mohajerzadeh, S., Ebrahimi, A., Robertson, M. D., "Low-temperature nickel-induced nano-crystallization of silicon on PET by MIC, hydrogenation and mechanical stress,"Solid-State Electronics, Vol.50 (2006), pp. 1618-1624.

(8) Pereira, L., Aguas, H., Beckers, M., Martins, R. M. S., Fortunato, E., Martins, R., "Spectroscopic ellipsometry study of nickel induced crystallization of a-Si," Journal of Non-Crystalline Solids, Vol.352 (2006), pp. 1204-1208.

(9) Yan, B., Shi, Y., Pu, L., Zhang, K., Han, P., Zhang, R., Zheng, Y., "Ni induced lateral crystallization of high density Ge-dots/Si heterostructures,"Mater. Lett, Vol.61 (2007), pp. 3711-3714.

(10) Hong, I. H., Hsu, T. C., Yen, S. C., Lin, F. S., Huang, M. L., Chen, C. H., "In situ spectromicroscopic study of nickel induced lateral crystallization of amorphous silicon thin film using SPESM," Surface Science, Vol.601 (2007), pp. 301-307.

(11) Grisenti, R., Dalba, G., Fornasini, P., Rocca, F., Koppolu, U. M. K., Krishna, M. G., "XAFS study of $\mathrm{Ni}$ surroundings in metal induced crystallization of thin film amorphous silicon," Solid State Communications, Vol.147 (2008), pp. 401-404.

(12) Cullity, B. D., "Elements of X-ray Diffraction, " 2nd ed.; Addison-Wesley Publishing Co. Inc. : London (1978). Scherrer Eq.

(13) Gall, Muske, M., Sieber, I., Schneider, J., Nast, O., Fuhs, W., "Polycrystalline silicon on glass by aluminum-induced," Preprint - 29th IEEE Photovoltaic Specialists Conference, New Orleans, Louisiana, USA (2002), pp.20-24. 